\title{
Pengaruh Kebijakan Dividen Terhadap Nilai Perusahaan yang Terdaftar dalam Indeks LQ 45
}

\author{
Debbi Chyntia Ovami \\ Universitas Muslim Nusantara $\mathrm{Al}$ \\ Washliyah \\ Medan, Indonesia \\ debbichyntiaovami@umnaw.ac.id
}

\author{
Ananda Anugrah Nasution \\ Universitas Muslim Nusantara Al \\ Washliyah \\ Medan, Indonesia \\ anandaanugrah@umnaw.ac.id
}

Corresponding Author : Debbi Chyntia Ovami

Submitted: 11 Juni 2020

Accepted: 23 Juni 2020

Published: 1 Agustus 2020

\begin{abstract}
$L Q 45$ is an index that is listed on the Indonesia Stock Exchange. The phenomenon that occurs in many companies that do not distribute dividends with cash even though this makes the company's profit. Dividend distributed by one of the company's strategies so that stock prices rise. An increase in stock prices will increase the value of the company. This study considers studying and analyzing dividend distribution policies on the value of companies approved at $L Q 45$. The number of studies in this study amounted to 45 companies and the sample was 51 companies using purposive sampling techniques. The technique of taking data in this study is documentation by taking data from the Indonesia Stock Exchange. The data analysis technique used is a simple regression analysis. The results showed that the dividend policy owned by the value of the company included in the LQ 45 Index on the Indonesia Stock Exchange
\end{abstract}

\begin{abstract}
ABSTRAK
LQ 45 merupakan indeks yang terdaftar di Bursa Efek Indonesia. Fenomena yang terjadi banyak perusahaan yang tidak membagikan dividen denga tunai padahal perusahan tersebut mendapatkan laba perusahaan . Dividen yang dibagikan salah satu strategi perusahaan agar harga saham mengalami kenaikan. Kenaikan harga saham akan mempengaruhi nilai perusahaan. Penelitian ini bertujuan untuk mengetahui dan menganalisis pengaruh kebijakan dividen terhadap nilai perusahaan yang terdaftar diperusahaan LQ 45. Jumlah populasi dalam penelitian ini sebesar 45 perusahaan dan sampelnya sebesar 51 perusahaan dengan menggunakan teknik purposive sampling. Teknik pengumpulan data dalam penelitian ini adalah dokumentasi dengan mengambil data dari bursa Efek Indonesia. Teknik analisis data yang digunakan adalah analisis regresi sederhana. Hasil penelitian menunjukkan bahwasanya kebijakan dividen mempunyai pengaruh terhadap nilai perusahaan yang terdaftar dalam Indeks LQ 45 di Bursa Efek Indonesia
\end{abstract}

Keywords : Kebijakan Dividen, Nilai perusahaan, DPR, PBV, LQ 45 


\section{PENDAHULUAN}

LQ-45 adalah indeks saham Bursa Efek Indonesia dimana terdiri dari 45 emiten yang memiliki kapitalisasi pasar terbesar dan nilai transaksi tertinggi dalam setahun terakhir ini. Perusahaan dapat masuk dalam indeks LQ45 apabila sudah menjadi anggota bursa minimal selama 3 bulan, kinerja keuangan dan prospek pertumbuhan tinggi. Banyak perusahaan yang terdaftar di BEI tidak membagikan dividen secara tunai, padahal emiten telah memperoleh laba. Selain itu ada juga emiten yang tidak membagikan dividen secara teratur kepada para pemegang saham. Melihat kondisi seperti ini, tentunya tidak sesuai dengan teori dari Gordon Litner yaitu "The Bird in the hand theory" yang menyatakan bahwasanya satu burung ditangan lebih berharga dibanding seribu burung diudara.

Kebijakan dividen adalah keputusan atas laba perusahaan dimana laba tersebut dibagikan kepada para pemegang saham dalam bentuk dividen atau menjadi laba ditahan untuk pembiayaan investasi pada masa yang akan datang (Harjito dan Martono, 2011). Selain itu, dividen menjadi hal yang sangat penting bagi perusahaan. Dividen dapat menunjukkan stabilitas perusahaan dan prospek kedepannya kepada pihak luar terutama investor yang akan melakukan investasi ke perusahaan yang dituju. Kemudian dividen juga dapat menunjukkan bagaimana keadaan kinerja keuangan perusahaan tersebut.

Dividen yang dibagikan adalah salah satu strategi untuk menaikkan harga saham. Harga saham meningkat. seiring dengan kenaikan dividen Jika perusahaan melakukan pembayaran dividen maka nilai perusahaan akan meningkat dan harga saham juga meningkat. Begitu juga sebaliknya jika perusahaan mengurangi pembagian dividen,maka kondisi perusahaan akan buruk dan menurunkan harga saham.
Nilai perusahaan sangat penting bagi perusahaan karena hal ini menjadi indikator penilaian perusahaan dan menunjukkan pertumbuhan perusahaan dimasa yang akan datang. Investor perlu menilai perkembangan perusahaan sebelum melakukan investasi dan juga manajemen perusahaan perlu melakukan analisis atas laporan keuangan perusahaan dan return yang akan diperoleh nantinya.

Banyak peneliti sudah melakukan penelitian dengan judul ini antara lain (Septariani 2017), (Manihuruk 2017), (Anita 2016) menyatakan bahwasanya kebijakan dividen berpengaruh dan tidak signifikan terhadap nilai perusahaan. (Nelwan 2018) menyatakan kebijakan dividen berpengaruh positif dan tidak signifikan terhadap nilai perusahaan. Sedangkan (Ganar 2018), (Senata 2016) menyatakan bahwasanya kebijakan dividen berpengaruh positif dan signifikan terhadap nilai perusahaan. Berdasarkan penelitian terdahulu, maka peneliti melakukan penelitian kembali pada indeks LQ-45 dengan tahun penelitian 2015-2017. Tujuan penelitian ini adalah untuk mengetahui dan menganalisis pengaruh kebijakan dividen terhadap nilai perusahaan pada perusahaan yang terdaftar dalam Indeks LQ 45.

\section{LANDASAN TEORI}

\subsection{Kebijakan Dividen}

Kebijakan dividen adalah keputusan perusahan dalam membagikan laba tersebut atau ditahan untuk dijadikan investasi kembali. Jika semakin tinggi dividen yang dibayarkan maka jumlah laba ditahan akan semakin kecil sehingga pertumbuhan perusahaan menjadi lambat begitujuga sebaliknya (Septariani 2017). Dividend payout ratio merupakan Persentase pendapatan/laba yang akan dibayarkan kepada pemegang saham (Warsini, 2003 dalam Rehulina dan Handoyo, 2014). Gumanti (2013:63) yaitu bahwasanya semakin dividen meningkat maka keyakinan manajer atas 
pertumbuhan laba semakin tinggi. Dividen yang naik akan memberikan sinyal kepada para investor tentang laba perusahaan. Investor akan membeli saham perusahaan jika dividen tinggi. Tentu hal ini akan meningkatkan harga saham.

\subsection{Nilai perusahaan}

Nilai perusahaan merupakan tingkat keberhasilan perusahaan yang dilihat salah satunya dari harga saham menurut para investor. Nilai perusahaan dipengaruhi oleh kinerja keuangan , jika kinerja keuangan semakin membaik, maka permintaan saham akan meningkat dan harga saham akan naik dan akhirnya perusahaan mempunyai nilai yang tinggi (Novari, 2016)

Indikator nilai perusahaan dilihat dari perbandingan nilai pasar dengan nilai buku. Nilai perusahaan yang diproksikan dengan Price to book value menunjukkan kemampuan perusahaan untuk menunjukkan nilai perusahaan terkait dengan harga saham terhadap modal perusahaan. Jika perusahaan dapat mengembalikan aset dengan tinggi maka nilai perusahaan akan tinggi dan begitu juga sebaliknya.

\subsection{Pengaruh Kebijakan Dividen terhadap nilai perusahaan}

Kebijakan dividen diproksikan dari Dividen payout ratio. Berdasarkan Theory Bird in the hand), semakin besar dividen maka akan menjadi daya tarik bagi pemegang saham. Hal ini dikarenakan investor lebih menyukai dividen dibandingkan capital gain. Semakin meningkatnya investor yang berinvestasi di perusahaan maka akan semakin tinggi harga saham dan selanjutnya akan meningkatkan nilai perusahaan (Gordon Linther dalam Brigham dan Joel ,2006:70)

\section{METODE PENELITIAN}

Metode penelitian yang digunakan adalah metode kuantitatif yang lebih menekankan pada analisis dan kemudian dilakukan pengujian hipotesis dan hasil akhirnya diperoleh adanya hubungan yang signifikan antar variabel. Populasi penelitian adalah 45 perusahaan dalam indeks LQ 45 tahun 2015-2017. Teknik sampling yang digunakan adalah purposive sampling. Adapun kriteria pemilihan sampel pada penelitian ini adalah sebagai berikut :

1. Perusahaan yang tercatat dalam indeks LQ-45 secara kontinue pada periode tahun 2015-2017.

2. Perusahaan yang membagikan deviden secara kontinue atau secara konsisten pada periode tahun 20152017.

Total sampel menjadi $17 \times 3$ tahun $=$ 51 sampel penelitian

Indikator pengukuran kebijakan dividen menggunakan Dividen Payout Ratio (DPR) sedangkan nilai perusahan diproksikan dengan Price Book Value (PBV) Teknik analisis data yang digunakan adalah analisis regresi sederhana

Dimana :

$$
\mathrm{Y}=\mathrm{a}+\mathrm{b}_{1} \mathrm{X}_{1}+\mathrm{e}
$$

$\mathrm{Y}=$ Nilai perusahaan

$\mathrm{a} \quad=$ Konstanta Persamaan Regresi

$\mathrm{b}_{1} \quad=$ Koefisien Regresi

$\mathrm{X}_{1}=$ Kebijakan Dividen

$\mathrm{e}=$ Error

\section{HASIL PENELITIAN}

\subsection{Uji Parsial (t)}

Hasil pengujian hipotesis pengaruh (kebijakan dividen) terhadap nilai perusahaan dapat dilihat tabel 1 berikut:

Tabel 1.Hasil Uji Parsial

\begin{tabular}{|c|c|c|c|c|c|}
\hline \multirow[t]{2}{*}{ Model } & \multicolumn{2}{|c|}{$\begin{array}{l}\text { Unstandardi } \\
\text { zd } \\
\text { Coefficients }\end{array}$} & \multirow{2}{*}{$\begin{array}{c}\text { Stand } \\
\text { ard } \\
\text { Coeff } \\
\text { icient } \\
\text { Beta }\end{array}$} & \multirow{2}{*}{ t } & \multirow{2}{*}{ Sig } \\
\hline & B & $\begin{array}{l}\text { Std. } \\
\text { Error }\end{array}$ & & & \\
\hline $1 \mid$\begin{tabular}{c|c} 
Consta \\
nt)
\end{tabular} & 1.329 & .573 & & 2.319 & .025 \\
\hline DPR & .037 & .011 & .452 & 3.280 & .002 \\
\hline
\end{tabular}

a. Dependent Variable : PBV 
Tabel di atas menunjukkan hasil pengujian statistik $t$ sehingga dapat menjelaskan pengaruh variabel independen secara parsial. Hasil penelitian pengaruh kebijakan dividen terhadap nilai perusahaan adalah sebagai berikut:

a. Nilai signifikansi sebesar 0,002 menunjukkan bahwa nilai Sig $\leq 0,05$. Sementara nilai koefisien sebesar 0,037. Hal ini sesuai dengan hasil pengujian statistik yang membandingkan antara $\mathrm{t}$ hitung dengan $t$ tabel, bahwa kebijakan dividen berpengaruh terhadap nilai perusahaan.

b. Variabel kebijakan dividen memiliki $\mathrm{t}$ hitung $(3,280)$ dengan nilai signifikansi $0,002 \leq 0,05$.Dengan menggunakan tabel $\mathrm{t}$ tabel, diperoleh $\mathrm{t}$ tabel sebesar (2,131). Hal ini menunjukkan bahwa t hitung sebesar 3,280 lebih besar dari t tabel sebesar 2,131, sehingga $\mathrm{HO}$ ditolak dan $\mathrm{Ha}$ diterima artinya, kebijakan dividen berpengaruh dan signifikan terhadap nilai perusahaan yang terdaftar dalam indeks LQ 45.

\subsection{Koefisien Determinasi}

Koefisien determinasi $\left(\mathrm{R}^{2}\right)$ digunakan untuk mengetahui pengaruh antar variabel yang diteliti. Hasil uji koefisien determinasi dapat dilihat pada tabel 2

Tabel 2 Hasil Uji Koefesien Determinasi $\left(\mathrm{R}^{2}\right)$

\begin{tabular}{|l|l|r|l|}
\hline Model & $\mathrm{R}$ & R Square & $\begin{array}{l}\text { Adjusted R } \\
\text { Square }\end{array}$ \\
\hline 1 & $.452^{\mathrm{a}}$ & .204 & .185 \\
\hline
\end{tabular}

a. Predictors: (Constant), DPR

b. Dependent Variable: PBV

Berdasarkan Tabel 2 nilai Koefisien (R) sebesar 0,452 yang menunjukkan besarnya hubungan antara variabel, dengan Adjusted $R$ square sebesar 0,185 atau $18,5 \%$. Hal ini berarti variabel kebijakan dividen dapat menjelaskan variabel nilai perusahaan sebesar $18,5 \%$. Sedangkan sisanya 81,5 $\%$ dijelaskan oleh variabel lain diluar model estimasi ini seperti profitabilitas, keputusan investasi, leverage dan lainnya.

\subsection{Analisis Regresi Sederhana}

Berdasarkan Tabel 1 maka diperoleh persamaan sebagai berikut:

$$
\begin{array}{cc}
\mathbf{P B V}=\mathbf{1 , 3 2 9}+\mathbf{0 , 0 3 7}+\mathbf{e} \\
\text { Konstanta } & \text { sebesar }
\end{array}
$$

menunjukkan besarnya nilai perusahaan yang diproksikan terhadap PBV (Price Book Value). Angka koefisien regresi sebesar 0,037 mempunyai arti bahwa setiap kenaikan 1 nilai DPR (Dividend Payout Ratio) juga akan meningkatkan nilai PBV sebanyak 0,037. Sedangkan e menunjukkan besarnya pengaruh faktor lain yang tidak dimasukkan di dalam model regresi.

\section{PEMBAHASAN}

Pengujian hipotesis yang dilakukan diketahui bahwa kebijakan dividen (X) memiliki nilai signifikansi sebesar 0,002 dan t hitung sebesar 3,280 dan koefisien regresi sebesar 0,037 . Nilai signifikansi 0,002 lebih kecil dari 0,05 atau t hitung lebih besar dari $t$ tabel $(3,280>2,131)$ sehingga tidak dapat menerima Ho yang berarti variabel kebijakan dividen (X) mempunyai pengaruh yang signifikan terhadap nilai perusahaan (Y).

Hasil penelitian ini menunjukkan bahwa perusahaan yang melakukan kebijakan dividen akan berpengaruh terhadap nilai perusahaan pada indeks LQ-45 yang terdaftar di Bursa Efek Indonesia. Aksi kebijakan dividen yang dilakukan oleh perusahaan dengan membagikan dividen tunai membuat saham perusahaan yang terdaftar di LQ45 semakin likuid. Karena sebagian investor menganggap aksi kebijakan 
dividen adalah sinyal positif dari perusahaan.

Penelitian ini didukung oleh teori signalling yang dikemukakan oleh Miller dalam Gumanti (2013:63) yaitu bahwasanya semakin dividen meningkat maka keyakinan manajer atas pertumbuhan laba semakin tinggi. Dividen yang naik akan memberikan sinyal kepada para investor tentang laba perusahaan. Investor akan membeli saham perusahaan jika dividen tinggi. Tentu hal ini akan meningkatkan harga saham. Selain itu hasil penelitian ini sejalan dengan penelitian yang dilakukan oleh (Ganar 2018), (Senata 2016) menyatakan kebijakan divididen berpengaruh positif dan signifikan terhadap nilai perusahaan.

Hasil penelitian ini bertolakbelakang dengan penelitian yang dilakukan (Septariani 2017), (Manihuruk 2017), dan (Anita 2016) yang menyatakan bahwa kebijakan dividen ini berpengaruh tidak signifikan terhadap nilai perusahaan. Hal ini sesuai dengan teori Miller dan Brigham yang menyatakan bahwa kebijakan dividen tidak mempengaruhi nilai perusahaan. Dividend Payout Ratio bukan untuk meningkatkan kesejahteraan para pemegang saham. Selain itu nilai perusahaan hanya bisa diukur melalui bagaimana perusahaan menghasilkan laba dari aset perusahaan atau kebijakan investasi.

\section{KESIMPULAN DAN SARAN}

\subsection{Kesimpulan}

Berdasarkan hasil penelitian dan pembahasan diatas, maka dapat disimpulkan bahwasanya kebijakan dividen yang diproksikan dengan Dividen payout Ratio (DPR) berpengaruh positif dan signifikan terhadap Nilai Perusahan yang diproksikan dengan Price Book Value $(P B V)$ pada perusahaan yang terdaftar dalam Indeks LQ 45 tahun 20152017.

\subsection{Saran}

1. Bagi Perusahaan

Sebaiknya perusahaan terus meningkatkan rasio pembayaran dividen agar para investor tertarik untuk membeli saham pada perusahaan tersebut, hal tersebut pasti akan berdampak pada kenaikan nilai perusahaan.

2. Bagi Investor

Ketika ingin membeli saham atau melakukan transaksi pada Bursa Efek sebaiknya perhatikan terlebih dahulu kebijakan dividennya. Jika perusahaan tersebut memiliki tingkat pembayaran dividen yang tinggi maka semakin tinggi nilai perusahaan.

3. Bagi Peneliti Selanjutnya

Untuk penelitian selanjutnya disarankan pengukuran nilai perusahaan menggunakan pengukuran lain seperti price earning ratio dan Tobins' $Q$ dan menggunakan sampel lain yang lebih banyak dan periode penelitian yang lebih terbaru. Penelitian yang selanjutnya juga menambah variabel independen lainnya seperti kebijakan investasi, profitabilitas dan leverage.

\section{DAFTAR PUSTAKA}

Anita, a. A. Y. (2016). Pengaruh Kepemilikan Manajerial Dan Kebijakan Dividen Terhadap Nilai Perusahaan. Management Analysis Journal, 5(1).

Brigham, Eugene F. dan Joel F. Houston. 2006. Manajemen Keuangan. Buku 1. Edisi X. Jakarta : Salemba Empat

Ganar, Y B. (2018). Pengaruh Kebijakan Dividen Dan Profitabilitas Terhadap Nilai Perusahaan Pada Perusahaan Yang Terdaftar Di Bursa Efek Indonesia Periode 2013- 2017 SEKURITAS, 2(1). 
Gumanti, Tatang Ary. 2013. Kebijakan Dividen Teori, Empiris dan Implikasi. Edisi Pertama Yogyakarta:UPP STIM YKPN

Harjito, Agus dan Martono. (2011). Manajemen Keuangan. Ekonisia. Fakultas Ekonomi, Universitas Islam Indonesia Yogyakarta

Manihuruk, d. (2017). Pengaruh Profitabilitas Dan Kebijakan Dividen Terhadap Nilai Perusahaan Pada Pt Unilever Indonesia, Tbk Yang Terdaftar Di Bursa Efek Indonesia. FINANCIAL, 3(1).

Nelwan, J. E. T. (2018). Pengaruh Kebijakan Dividen, Keputusan Pendanaan Dan Keputusan Investasi Terhadap Nilai Perusahaan Pada Saham Bluechip Yang Terdaftar Di BEI. EMBA, 6(4), 2878-2887

Novari, Putu Mikhy, Pupu Vivi Lestari. 2016. Pengaruh Ukuran Perusahaan, Leverage, dan Profitabilitas Terhadap Nilai Perusahaan Pada Sektor Properti Dan Real Estate. E-JURNAL MANAJEMEN UNUD 5(9),56715694.

Rehulina, Novi Sitepu dan Handoyo C Wibisono. (2014). Pengaruh Kebijakan Dividen, Kebijakan Leverage dan Profitabilitas Terhadap Nilai Perusahaan Manufaktur Yang Terdaftar Di BEI Pada Tahun 2009-2013. Program Studi Manajemen, Fakultas Ekonomi, Universitas Atma Jaya Yogyakarta.

Senata, M. (2016). Pengaruh Kebijakan Dividen Terhadap Nilai Perusahaan Yang Tercatat Pada Indeks LQ-45 Bursa Efek
Indonesia. Jurnal Wira Ekonomi Mikroskil 6(1).

Septariani, d. (2017). Pengaruh Kebijakan Dividen Dan Kebijakan Hutang Terhadap Nilai Perusahaan (Studi Empiris Pada Perusahaan LQ 45 di BEI periode 20122015). Journal of Applied Business And Economics, 3(3), 183-195. 